11,13

\title{
Структурная гетероэпитаксия при топохимическом превращении кремния в карбид кремния
}

\author{
() В.К. Егоров ${ }^{1}$, Е.В. Егоров ${ }^{1}$, С.А. Кукушкин ${ }^{2-5,9}$, А.В. Осипов ${ }^{2-4}$ \\ ${ }^{1}$ Институт проблем технологии микроэлектроники и особо чистых материалов РАН, \\ Черноголовка, Россия \\ ${ }^{2}$ Институт проблем машиноведения РАН, \\ Санкт-Петербург, Россия \\ ${ }^{3}$ Санкт-Петербургский академический университет, \\ Санкт-Петербург, Россия \\ ${ }^{4}$ Санкт-Петербургский национальный исследовательский университет \\ информационных технологий, механики и оптики, \\ Санкт-Петербург, Россия \\ ${ }^{5}$ Санкт-Петербургский государственный политехнический университет, \\ Санкт-Петербург, Россия \\ ฯ E-mail: sergey.a.kukushkin@gmail.com
}

(Поступила в Редакцию 27 июня 2016 г.)

Методом каналирования ионов исследованы образцы карбида кремния, синтезированные из кремния методом топохимического замещения атомов. Результаты анализа однозначно доказывают наличие структурной гетероэпитаксии. Решетка синтезируемого карбида кремния гексагонального политипа $6 H$ эпитаксиально согласована в направлении $\langle 0001\rangle$ с решеткой исходного кремния подложки в направлении $\langle 111\rangle$. Выявлены основные особенности структурного самосогласования в этом эпитаксиальном гетерокомпозите. Несмотря на очень большое несоответствие параметров решеток карбида кремния и кремния, плотность дислокаций несоответствия на границе раздела невелика, что является особенностью метода топохимического замещения атомов, приводящего к соизмеримым структурам.

В.К.Е и Е.В.Е выражают благодарность за финансовую поддержку РФФИ (проекты № 15-08-02618-a и 16-07-00665), С.А.К. и А.В.О. выражают благодарность за финансовую поддержку РНФ (грант № 14-22-00018).

DOI: 10.21883/FTT.2017.04.44279.261

\section{1. Введение}

Главной отличительной чертой монокристаллического строения материала является наличие строго упорядоченного расположения атомов в их кристаллографических позициях, соответствующего группе симметрии кристаллической решетки, с жестко фиксированными расстояниями между центрами атомов. В этих центрах сосредоточена масса атомов, в основном определяемая массой их ядер, и положительный заряд, соответствующий их атомному номеру. Наличие строгого упорядочения позволяет рассматривать монокристаллический материал как совокупность атомных цепочек, ориентированных вдоль главных кристаллографических направлений в кристалле. При попадании в потенциальную яму между атомными цепочками быстрые положительно заряженные частицы начинают двигаться по осциллирующим траекториям, период колебательного флуктуирования которых зависит от энергии иона, от расстояния до атомных ядер материала при входе иона в ориентированную кристаллическую решетку, а также от угла между кристаллографической осью, соответствующей направлению упорядочения атомов в структуре, и направлением распространения ионного потока $[1,2]$. Такой тип движения ионов в кристаллическом матери- але принято называть осевым каналированием ионного потока. Он характеризуется более глубоким проникновением потока ионов в объем материала, с которым он взаимодействует в сравнении с глубиной, на которую он проникает в хаотически ориентированный монокристалл или в материал с тем же элементным составом в аморфном или поликристаллическом состоянии. Монокристаллическое строение материала может быть представлено в форме упорядоченного расположения не только атомных цепочек, но и атомных плоскостей. При ориентированном попадании ионного потока в межплоскостные области кристалла также наблюдается каналирование, которое принято называть плоскостным. В сравнении с осевым, плоскостное каналирование ионов является менее ярким эффектом и используется в экспериментальных исследованиях лишь для решения узкоспециализированных задач [3].

В экспериментальном плане явление каналирования ионов в монокристаллах приводит к резкому снижению интенсивности выхода ионов, рассеянных на ядpax атомов зондируемого материала. Эффект рассеяния ионов на ядрах атомов конденсированных материалов достаточно точно описывается формулой Резерфорда, предполагающей упругое взаимодействие положительно заряженного иона с положительно заряженным по- 
коящимся ядром атома. Этот подход оправдан для описания рассеяния ионных пучков средних энергий $\left(E_{0}=0.5-2.5 \mathrm{MeV}\right)$ в предположении статистического распределенния атомов по объему тестируемого материала, т.е. для монокристаллов при их случайной ориентации относительно направления распространения ионного потока или для материалов в аморфном или поликристаллическом состоянии. С учетом атомной плотности материалов резерфордовский подход позволяет адекватно описывать эффект взаимодействия ионного потока с веществом [1]. При наличии ориентационного соответствия между направлением распространения ионного потока и одной из главных кристаллографических осей исследуемого монокристалла наблюдается существенное уменьшение эффективности рассеяния ионного потока за счет захвата части ионов в осевые кристаллические каналы. При осевом каналировании глубина проникновения ионов внутрь кристалла увеличивается в 3-5 раз из-за уменьшения тормозных потерь. Такое уменьшение, в свою очередь, является отражением снижения степени взаимодействия с электронами внутренних оболочек атомов. Поэтому в условиях каналирования помимо уменьшения выхода рассеяния ионов снижается и выход рентгеновской флуоресценции, вызываемой ионным возбуждением. Но одновременно увеличивается выход ионолюминесценции, обусловленной взаимодействием с внешними электронами.

Ключевой особенностью явления каналирования в монокристаллах является возможность отличать наличие монокристалличности (или гетероэпитаксии) от высококачественного текстурирования. В рентгенодифракционном анализе материалов принято, что для установления монокристалличности материала или наличия эпитаксии в гетерокомпозите необходимо и достаточно регистрации отражений общего вида $(h k l)$, у которых все три индекса диагностируемого рефлекса не равны нулю. Однако наши последние исследования гетероструктуры $\mathrm{Au} /$ мусковит показали, что наличие рефлексов с ненулевыми индексами не является достаточным фактором, доказывающим полное ориентационное соответствие пленочной и подложечной структуры [4]. Реальным фактором, доказывающим наличие гетероэпитаксии в гетерокомпозитных структурах, представляется наблюдение в них осевого каналирования ионных потоков. Возможность каналирования ионов - это прямое следствие наличия ориентационного соответствия между сопрягаемыми кристаллическими структурами по всем трем кристаллографическим осям. Поэтому в настоящей работе для исследования возможного ориентационного согласия гексагональной структуры карбида кремния $\mathrm{SiC}$, выращенного из кремния $\mathrm{Si}$ методом топохимического замещения атомов, и кубической структуры $\mathrm{Si}$ помимо дифрактометрических исследований был выполнен анализ экспериментальных гетероструктур $\mathrm{SiC} / \mathrm{Si}$ с помощью каналирования потоков ионов гелия и водорода. Для этих исследований были использованы аналитические возможности ионно-пучкового комплекса Сокол-3 [5].

\section{2. Метод топохимического замещения атомов кремния на атомы углерода}

Разработка технологий получения монокристаллических пленок карбида кремния с совершенной кристаллической структурой на кремниевых подложках представляется весьма актуальным направлением развития наноэлектроники и фотоники, с одной стороны, вследствие широкой распространенности и доступности кремниевых технологий, а с другой - ввиду настоятельной необходимости наличия дешевых структурносовершенных подложек для построения наноэлементных устройств на основе широкозонных полупроводников, таких как $\mathrm{GaN}, \mathrm{AlN}, \mathrm{BN}, \mathrm{ZnO}$. В настоящее время развита технология выращивания монокристаллов $\mathrm{SiC}$ и освоено производство подложечного материала на базе $\mathrm{SiC}$. Однако стоимость подобных пластин крайне высока, и их использование плохо сочетается с кремниевой технологией. Поэтому, несмотря на существенные структурные и термические различия $\mathrm{Si}$ и $\mathrm{SiC}$, регулярно предпринимаются попытки получения пленок $\mathrm{SiC}$ на кремнии. Одной из успешных попыток вырастить эпитаксиальный $\mathrm{SiC}$ на $\mathrm{Si}$ является топохимический синтез $\mathrm{SiC}$ непосредственно из самой подложки $\mathrm{Si}$ методом замещения атомов [6-9]. Технически данный метод реализуется помещением монокристаллической кремниевой подложки выбранной ориентации в газовую среду моноокиси углерода СО и подбором давления газа и температуры нагрева кремния. При определенных условиях между $\mathrm{Si}$ и СО происходит двухстадийная топохимическая реакция с образованием конденсированных молекул $\mathrm{SiC}$ и газообразных молекул моноокиси кремния $\mathrm{SiO}[6,7,10,11]$. При этом существенно, что в конденсированном состоянии одна молекула $\mathrm{SiC}$ заменяет два атома кремния, т.е. в области протекания твердофазной реакции появляются структурные вакансии. Возникновение вакансий позволяет существенно снизить значения упругих напряжений, связанных с различием размеров элементарных ячеек $\mathrm{Si}$ и $\mathrm{SiC}$, а также унаследовать ориентационную зависимость структуры появляющейся карбидной фазы от исходной кремниевой материнской структуры $[6,10]$. Например, если выбранные термодинамические условия способствуют возникновению гексагональных политипов $\mathrm{SiC}$ на $\mathrm{Si}(111)$, то наличие структурных вакансий позволяет добиться ориентационного соответствия между кристаллографическим направлением кремниевой матрицы $\langle 111\rangle$ и гексагональной осью карбидных политипов [6]. Дальнейший рост пленки карбидной фазы осуществляется за счет высокой вероятности проникновения газовых молекул $\mathrm{CO}$ в структуру $\mathrm{SiC}$ и выхода газовых молекул $\mathrm{SiO}$ из $\mathrm{SiC}$.

Важной особенностью метода замещения атомов является то, что структурные вакансии, возникающие в кремнии в ходе топохимической реакции, оказываются не связанными с кристаллической решеткой $\mathrm{SiC}$, a сосредоточиваются под покрытием, тем самым образуя буферную зону между структурами пленки и подложки. 
Эта зона, с одной стороны, сохраняет ориентационные свойства гетероструктуры, а с другой - позволяет компенсировать различие в коэффициентах термического расширения $\mathrm{Si}$ и $\mathrm{SiC}$.

Разработка подобной технологии ориентационного сопряжения, казалось бы, совершенно не сопрягаемых кристаллических структур, является крайне полезной и перспективной в техническом плане, поскольку позволяет совместить широко развитые кремниевые технологии с методами приготовления гетероструктур на базе широкозонных полупроводников для СВЧ и оптоэлектроники. Разработанные модели данного топохимического метода твердофазной эпитаксии $[6,11]$ дают основания предполагать, что получаемые гетероструктуры характеризуются действительным эпитаксиальным соответствием пленок $\mathrm{SiC}$ и подложек $\mathrm{Si}$, т.е. полным кристаллографическим ориентационным соответствием по всем трем кристаллографическим направлениям. Поскольку подтвердить или опровергнуть это предположение можно только с использованием каналирования ионов в гетероструктурах, в настоящей работе проведено данное исследование с использованием уникальной научной установки - ионно-пучкового комплекса Сокол-3 (УНУ № 45) совместно с дифрактометрическим анализом. Исследовались пленки $\mathrm{SiC}$ толщиной $100-120 \mathrm{~nm}$, выращенные топохимическим замещением атомов на подложках $\mathrm{Si}(111)$ при температуре $1230^{\circ} \mathrm{C}$ и давлении CO, равном $270 \mathrm{~Pa}[6-8]$.

\section{3. Изучение структурной гетероэпитаксии в гетероструктурах $\mathrm{SIC} / \mathrm{SI}$}

Изучение гетероструктур $\mathrm{SiC} / \mathrm{Si}(111)$ было начато с их дифрактометрического анализа. На рис. 1 показан фрагмент дифрактограммы одной из таких гетероструктур, полученной с использованием источника излучения БСВ-27 $(\mathrm{Cu})$ в фокусирующей геометрии Брэгга-Брентано. На рентгенограмме представлены интенсивные рефлексы линий $\mathrm{Cu} K_{\alpha}$ и $\mathrm{Cu} K_{\beta}$, характеризующие ориентацию структуры подложки, при которой кристаллографическая ось $\langle 111\rangle$ перпендикулярна поверхности гетероструктуры. Там же наблюдаются пики дифракции линий $\mathrm{Cu} K_{\alpha}, \mathrm{Cu} K_{\beta}$ на $\mathrm{SiC}(006)$ показывающие ориентацию пленочной структуры $\mathrm{SiC}$ гексагональной осью перпендикулярно плоской поверхности гетероструктуры, но при этом демонстрирующие значительное уширение. Представленная на рис. 1 дифрактограмма показывает наличие осевого соответствия между кристаллографическим направлением подложки $\langle 111\rangle$ и гексагональной осью $\langle 0001\rangle$ пленки карбида кремния. Такое соответствие может наблюдаться как при наличии эпитаксии, так и в условиях образования текстуры [4]. При этом существенно отметить, что плоскость (111) кремниевой структуры характеризуется гексагональной

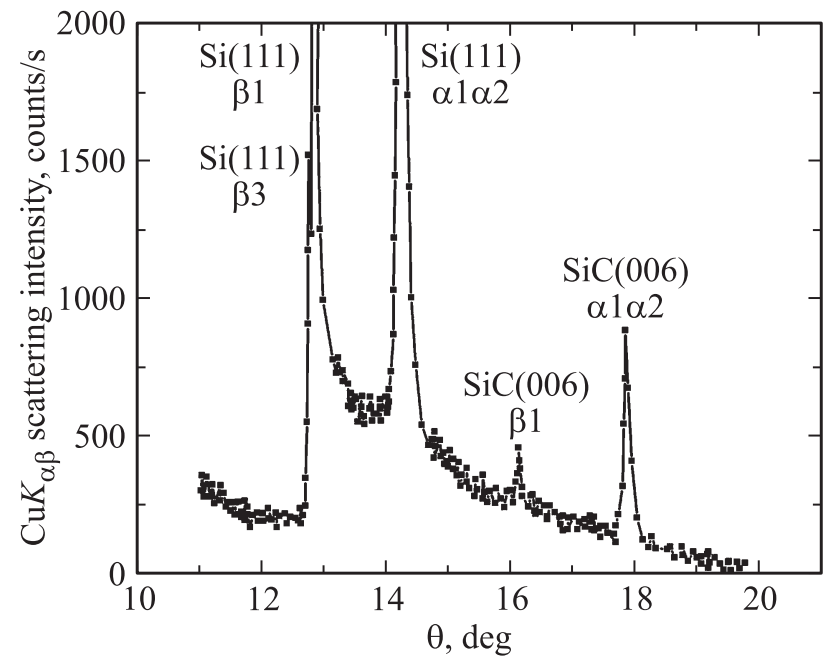

Рис. 1. Фрагмент дифрактограммы гетероструктуры $6 H-\mathrm{SiC}(0001) / \mathrm{Si}(111)$, полученный в фокусирующей геометрии Брэгга-Брентано. Видно наличие осевого соответствия между кристаллографическим направлением подложки $\langle 111\rangle$ и гексагональной осью пленки $6 H-\mathrm{SiC}$.

сеткой плотной упаковки с размерами гексагона, равными $0.443 \times 0.384 \mathrm{~nm}$ (рис. $2, a)$, а сетка плотной упаковки атомов в плоскости $(0001)$ структуры $6 H$-SiC имеет размер гексагона $0.357 \times 0.308 \mathrm{~nm}$ (рис. $2, b)$. Отношение размеров гексагонов $\mathrm{SiC}$ к $\mathrm{Si}$ равно 0.80 . В такой ситуации прямое эпитаксиальное сращивание пленочной и подложечной структур практически невозможно. Лишь метод замещения атомов обеспечивает эпитаксиальное сращивание соизмеримых структур пленки и подложки за счет формирования пор усадки [6,7]. Пять ячеек $\mathrm{SiC}$ сращиваются с четырьмя ячейками $\mathrm{Si}$ (рис. 3), при этом дислокации несоответствия решеток почти не образуются [6,7]. Механизм сращивания и образования пор усадки подробно обсуждается в обзоре [7]. Отметим, что при усадке материала возможно образование дислокаций, двойников, вакансий и пор. В случае роста $\mathrm{SiC}$ методом замещения атомов усадочные поры, как показано в работе [7], можно „залечить“. Для этого в процессе синтеза пленки одновременно с газом СО в систему подается поток силана $\left(\mathrm{SiH}_{4}\right)$, концентрация и скорость подачи которого, строго вычисляются [7]. Однако „залечивание“ усадочных пор в основном происходит на поверхности пленки. В глубине пленки образуются двойники. Двойники образуются и при отклонении параметров роста от оптимальных. При двойниковании нарушается правильная последовательность в чередовании укладки атомов в кристалле. Образование двойников - один из возможных и для данной задачи нежелательный процесс пластической деформации и релаксации упругой энергии, вызванной различием в параметрах решеток $\mathrm{Si}$ и $\mathrm{SiC}$. Двойникование можно описать при помощи введения частичных дислокаций. Именно двойники присутствуют в пленках $\mathrm{SiC}$, выращенных методом замещения атомов, 


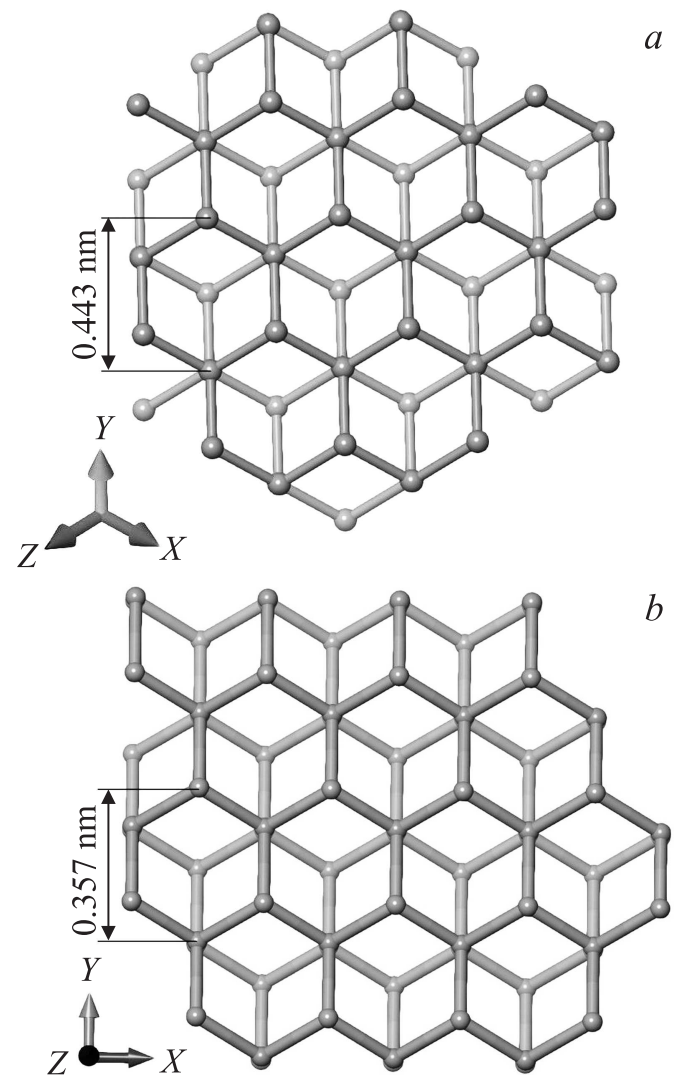

Рис. 2. Периодическая структура атомов $\mathrm{Si}$ в направлении $\langle 111\rangle(a)$ и молекул $\mathrm{SiC}$ в кристалле $6 H-\mathrm{SiC}(b)$ в направлении гексагональной оси $\langle 0001\rangle$. Поскольку отношение характерных размеров структур $\mathrm{SiC}$ к $\mathrm{Si}$ равно 0.80, то эти структуры соизмеримы: на пять ячеек $\mathrm{SiC}$ приходится четыре ячейки $\mathrm{Si}$.

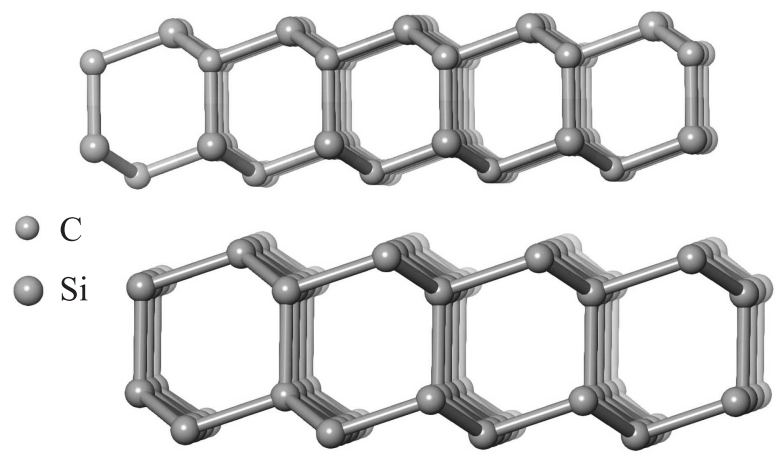

Рис. 3. Гетероэпитаксиальное сопряжение соизмеримых структур пленки $\mathrm{SiC}$ и подложки $\mathrm{Si}$.

в то время как дислокации несоответствия, являющиеся основными дефектами при росте пленок стандартными методами, в данном материале отсутствуют [7].

В качестве первой задачи ионно-пучковой диагностики гетероструктур SIC/Si рассматривался анализ распределения элементов по толщине, который позволяет аналитически реконструировать результаты технологического процесса. На рис. 4 представлены экспериментальные спектры резерфордовского обратного рассеяния (РОР) ионных пучков гелия $(a)$ и водорода $(b)$, измеренные детектором $D_{1}$ (показан на вставке) для гетероструктуры $6 H-\mathrm{SiC} / \mathrm{Si}$, и теоретические огибающие, которые позволяют аппроксимировать элементный концентрационный профиль. Спектр РОР ионов $\mathrm{He}^{+}$описывается двухступенчатой кривой, огибающая которой в области больших каналов отчетливо разделяется на область пониженного содержания атомов кремния и область подложки, а также демонстрирует изгиб в малых каналах, связанный с наличием атомов углерода в пленке $\mathrm{SiC}$. Спектр POP ионов водорода имеет заметно отличающуюся огибающую. На этом спектре область пониженного содержания атомов кремния, связанная с появлением пленки карбида кремния на поверхности гетероструктуры, выражена слабо. В то же время эта область хорошо очерчена мощным пиком, отражающим наличие атомов углерода
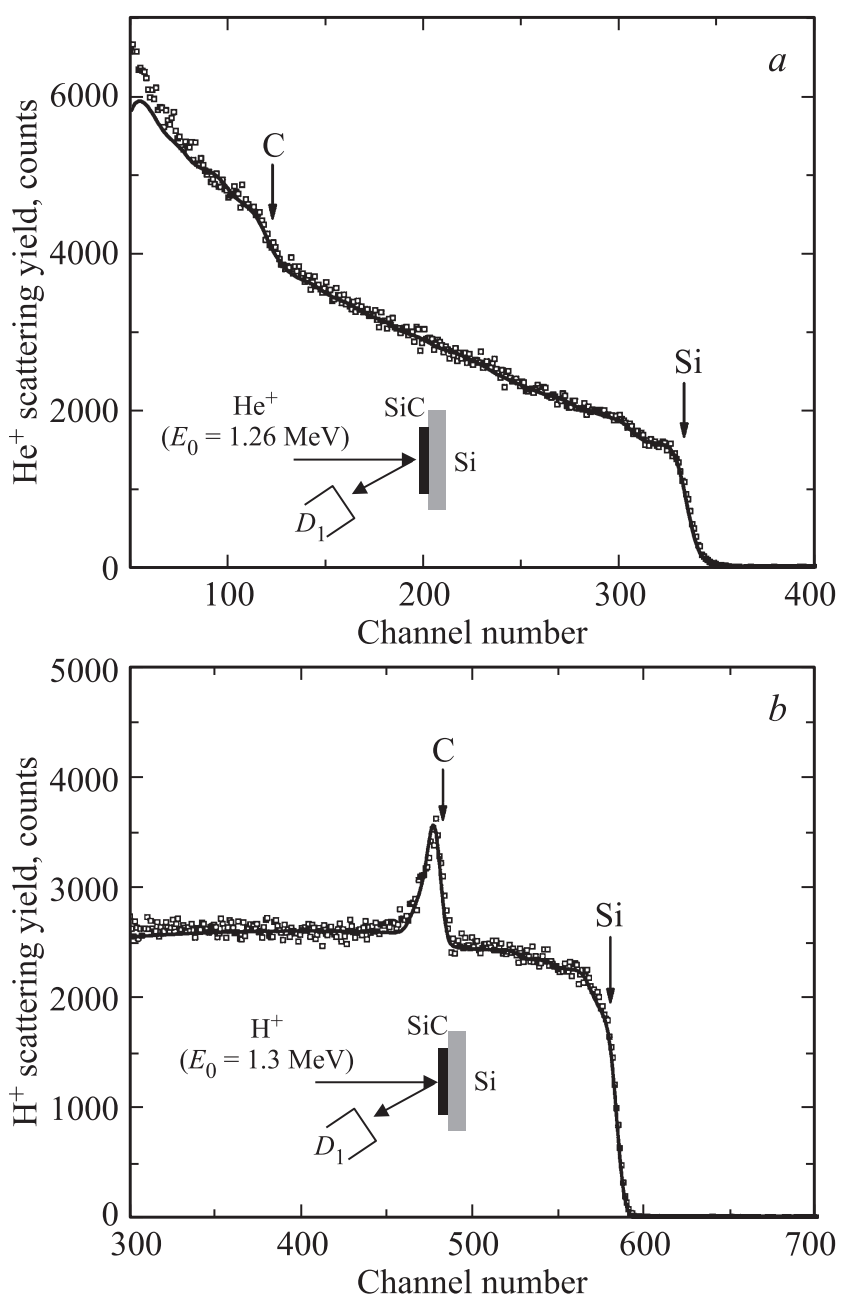

Рис. 4. Экспериментальные (символы) и теоретические (сплошные линии) спектры РОР потоков ионов $\mathrm{He}^{+}$ $\left(E_{0}=1.26 \mathrm{MeV}\right) \quad(a)$ и $\mathrm{H}^{+}\left(E_{0}=1.3 \mathrm{MeV}\right) \quad(b)$ для гетероструктуры $6 H-\mathrm{SiC} / \mathrm{Si}$, полученные в условиях случайной ориентации мишени относительно направления распространения ионных потоков. Энергетический шаг $1.9 \mathrm{keV} /$ канал. 
Результаты аппроксимации комплекта спектров РОР ионов $\mathrm{He}^{+}$и $\mathrm{H}^{+}$, полученных для гетероструктуры $6 H-\mathrm{SiC} / \mathrm{Si}$, выращенной методом топохимического замещения атомов при температуре $1230^{\circ} \mathrm{C}$

\begin{tabular}{c|c|c|c}
\hline № & $\begin{array}{c}\text { Состав, усредненный } \\
\text { по толщине слоя }\end{array}$ & Толщина, $\mathrm{nm}$ & Примечание \\
\hline 1 & $\mathrm{Si}_{1} \mathrm{C}_{1}$ & $75 \pm 5$ & Гомогенен по толщине \\
2 & $0.6 \mathrm{Si}_{1} \mathrm{C}_{1}+0.4 \mathrm{Si}_{1}$ & $100 \pm 10$ & Наблюдается вариация состава \\
3 & $0.85 \mathrm{Si}_{0.75} \mathrm{C}_{0.25}+0.15 \mathrm{Si}_{1} \mathrm{C}_{1}$ & $100 \pm 10$ & Не гомогенен \\
4 & $0.9 \mathrm{Si}_{0.8} \mathrm{C}_{0.2}+0.1 \mathrm{Si}_{1} \mathrm{C}_{1}$ & $100 \pm 10$ & $\gg \gg \gg$ \\
5 & $0.95 \mathrm{Si}_{0.9} \mathrm{C}_{0.1}+0.05 \mathrm{Si}_{1} \mathrm{C}_{1}$ & $500 \pm 50$ & $\gg \gg$ \\
6 & $\mathrm{Si}_{0.94} \mathrm{C}_{0.06}$ & $500 \pm 50$ & Подложка
\end{tabular}

в этом покрытии. Его заметная интенсивность как раз определяется значительным нерезерфордовским вкладом рассеяния ионов водорода на ядрах атомов углерода. Аппроксимация спектров, показанных на рис. 4, вместе со спектрами, зарегистрированными вторым детектором, установленным под углом к направлению распространения ионных потоков $120^{\circ}$, проводилась с помощью пакета программ RUMPP, который является результатом выполненной нами модификации аппроксимационной интерактивной программы RUMP [12]. Эта аппроксимация показала, что пленка $\mathrm{SiC}$ имеет двухслойную структуру с практически гомогенным составом верхнего слоя. Между пленкой карбида кремния и подложкой располагается промежуточная зона толщиной около $1.5 \mu \mathrm{m}$ с пористой структурой, причем концентрация вакансий в этой зоне гетероструктуры меняется от $40 \%$ at. вблизи пленки карбида кремния до нулевого значения в конце. Следует заметить, что монотонный рост интенсивности рассеяния на спектре рассеяния ионов гелия в интервале каналов 100-300 характеризует именно эту зону. Результаты аппроксимационной обработки всего комплекта спектров резерфордовского обратного рассеяния для двух исследованных нами гетероструктур $6 \mathrm{H}-\mathrm{SiC} / \mathrm{Si}$ сведены в таблицу послойного распределения элементов и вакансий. По существу, данные резерфордовского обратного рассеяния полностью совпадают с соответствующими данными эллипсометрии [13] с той лишь разницей, что эллипсометрия не может установить наличие $\mathrm{SiC}$ внутри самой подложки $\mathrm{Si}$, тогда как POP регистрирует $\mathrm{SiC}$ в $\mathrm{Si}$ на глубине вплоть до $1.5 \mu \mathrm{m}$.

Следующей задачей ионно-пучковой диагностики гетероструктуры $6 \mathrm{H}-\mathrm{SiC} / \mathrm{Si}$ являлось экспериментальное установление факта наличия-отсутствия структурной эпитаксии, т.е. наличие-отсутствие ориентационного соответствия по всем трем кристаллографическим направлениям сопрягаемых структур. Для решения этой задачи были проведены поиски условий возможного каналирования потоков ионов гелия и водорода вдоль оси соответствия, совпадающей с кристаллографическим направлением [001] в поверхностной пленочной структуpe $6 H-\mathrm{SiC}$ и кристаллографическим направлением [111] кремниевой монокристаллической подложки. Были изу- чены спектры POР потока ионов $\mathrm{He}^{+}\left(E_{0}=1.2 \mathrm{MeV}\right)$, полученные для случайной ориентации гетероструктуры $6 \mathrm{H}-\mathrm{SiC} / \mathrm{Si}$ относительно направления распространения потока ионов, и для случая, когда ось согласия сопрягаемых структур совпадает с направлением распространения ионного потока. Для указанных условий спектры POP регистрировались обоими детекторами, установленными под углами к направлению распространения потока $\theta_{1}=160^{\circ}$ и $\theta_{2}=120^{\circ}$. Обнаруженное различие в спектрах имело место только в области верхнего слоя, имеющего стехиометрию $\mathrm{SiC}$, толщиной $75 \mathrm{~nm}$. При этом снижение интенсивности выхода рассеяния на ядрах атомов $\mathrm{Si}$, принадлежащих к этому слою, составляло 3-4\%. Полученная спектральная информация позволяет сделать вывод, что поверхностный стехиометрический слой $\mathrm{SiC}$ имеет монокристаллическое строение, но при этом характеризуется нарушением кристаллической упаковки, что несколько снижает совершенство его структуры. При движении от поверхности пленки к кремнию, возрастает плотность двойников, что ведет к росту дефектности слоев $\mathrm{SiC}$. Это, в свою очередь, приводит к тому, что явление каналирования ионов гелия в более глубоких слоях не может проявиться из-за значительного углового размытия исходного ионного потока. Таким образом, тестирование гетероструктуры $6 H-\mathrm{SiC} / \mathrm{Si}$ потоком ионов гелия с энергией $1.2 \mathrm{MeV}$ не позволяет ответить на вопрос о наличии или отсутствии в ней структурной эпитаксии. В этом плане тестирование данной гетероструктуры пучком ионов водорода представляется более перспективным, поскольку тормозные потери ионов водорода, связанные с взаимодействием с электронной подсистемой материалов, приблизительно на порядок меньше в сравнении с тормозными потерями ионов гелия [14]. На рис. 5 показаны экспериментальные спектры РОР потока ионов водорода $\left(E_{0}=1.1 \mathrm{MeV}\right)$, полученные для случайной ориентации гетероструктуры $6 \mathrm{H}-\mathrm{SiC} / \mathrm{Si}$ относительно направления распространения ионного потока, а также в условиях совпадения этого направления с осью ориентационного соответствия монокристаллической пленки $\mathrm{SiC}$ и подложки Si. Регистрация спектров осуществлялась обоими детекторами экспериментальной камеры, расположенны- 
ми под углами рассеяния по отношению к направлению распространения исходного ионного потока $\theta_{1}=160^{\circ}$ и $\theta_{2}=120^{\circ}$. Сравнение спектров, зарегистрированных в ориентированном и неориентированном положении гетероструктуры, демонстрирует некоторое уменьшение выхода рассеяния в ее ориентированном положении для поверхностного слоя толщиной около $1.5 \mu \mathrm{m}$. Причем это отчетливо заметно при сравнении спектров РОР, зарегистрированных детектором, соответствующим углу рассеяния потока $\theta_{1}=160^{\circ} \mathrm{C}$. Для спектров РОР, зарегистрированных вторым детектором $\theta_{2}=120^{\circ}$, различие в спектрах, полученных в ориентированном и неориентированном положениях гетероструктуры, наблюдается
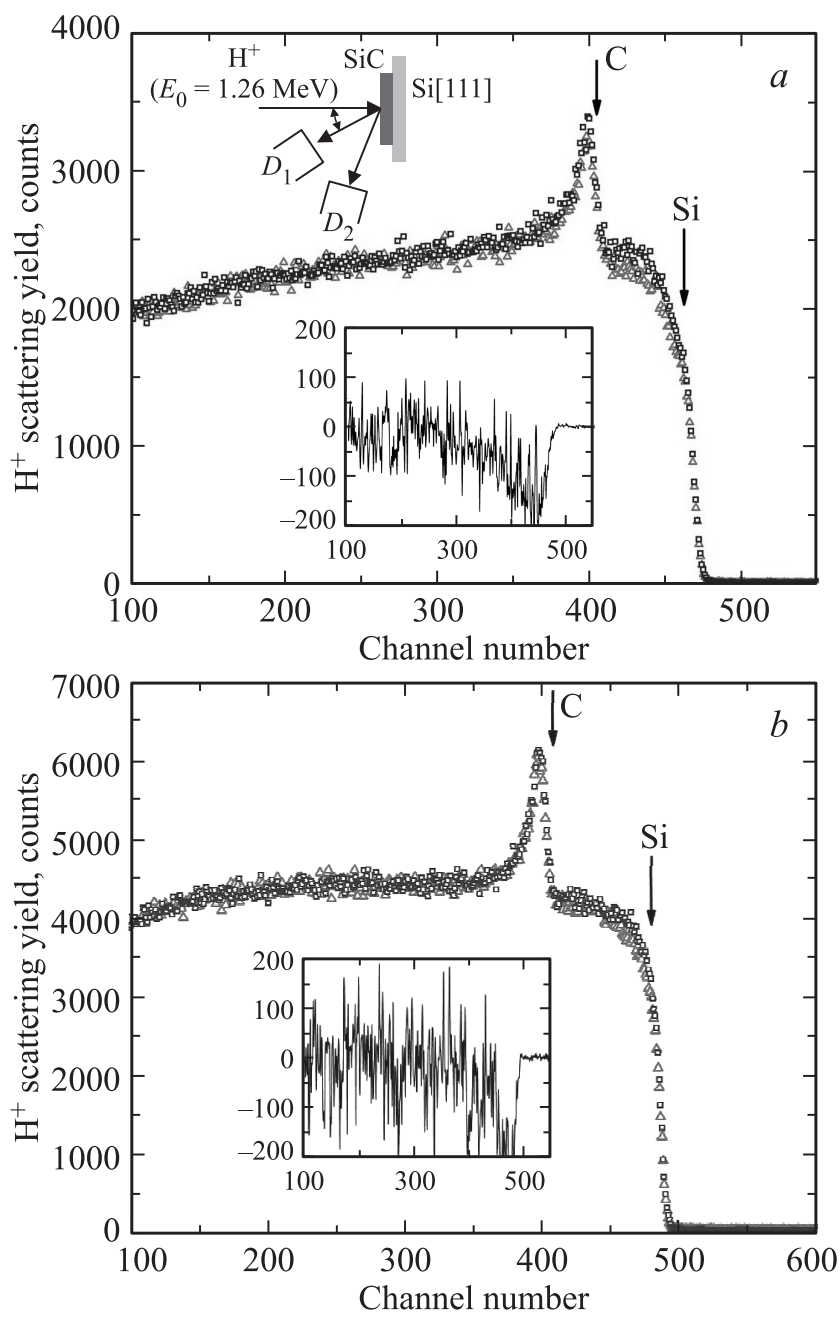

Pис. 5. Спектры РОР потока ионов $\mathrm{H}^{+}\left(E_{0}=1.1 \mathrm{MeV}\right)$, полученные для случайной ориентации гетероструктуры $6 H-\mathrm{SiC} / \mathrm{Si}$ относительно направления распространения потока ионов (треугольники) и в условиях согласия оси сопрягаемых структур с направлением распространения потока (квадраты). Спектры регистрировались одновременно детекторами $D_{1}$ и $D_{2}$ под углами рассеяния $\theta_{1}=160^{\circ}(a)$ и $\theta_{2}=120^{\circ}(b)$. На вставках изображена геометрия измерений и разности спектров для неориентированного и ориентированного положений гетероструктуры. Энергетический шаг $1.9 \mathrm{keV} /$ канал. Стрелками указаны энергии рассеяния ядрами поверхностных атомов.

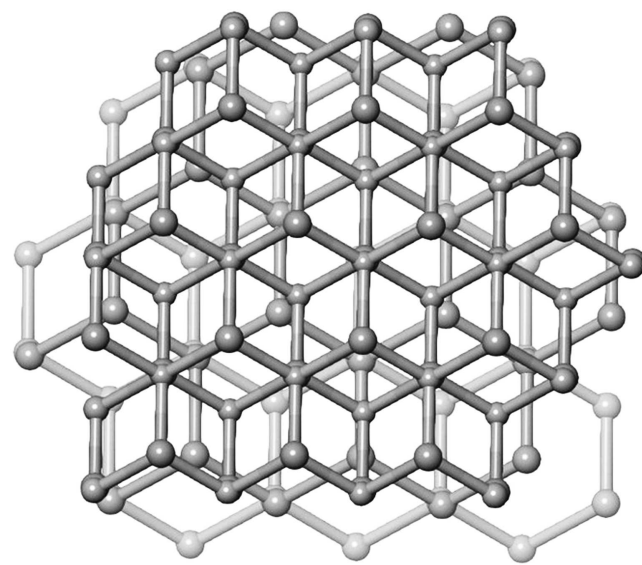

Рис. 6. Общий вид каналов, образуемых соизмеримой гетероструктурой $6 H-\mathrm{SiC}(0001) / \mathrm{Si}(111)$. Лишь $4 \%$ гексагонов $\mathrm{SiC}$ и 7\% гексагонов $\mathrm{Si}$ согласованы друг с другом, что приводит к невысокой разнице в интенсивностях РОР потока ионов, полученного для случайной ориентации гетероструктуры $6 H-\mathrm{SiC} / \mathrm{Si}$ относительно направления потока ионов, а также при совпадении потока ионов с осью пленки $\mathrm{SiC}$ и подложки $\mathrm{Si}$.

для поверхностной слоевой структуры толщиной около $0.3 \mu \mathrm{m}$. Сопоставление данных по каналированию потока ионов водорода в гетероструктуре $6 \mathrm{H}-\mathrm{SiC} / \mathrm{Si}$, полученной методом замещения атомов, и результатов элементного концентрационного профилирования по толщине этой мишени, представленных в таблице, позволяет утверждать, что в ней действительно наблюдается эпитаксиальное соответствие, причем по всей слоевой структуре. Значение параметра осевого каналирования для всей гетероструктуры в целом не является стационарным параметром, т.е. варьируется от слоя к слою в интервале 0.93-0.98 по спектрам, полученным с помощью первого детектора, и 0.95-1.00 по спектрам, зарегистрированным вторым детектором. Этот результат является вполне ожидаемым для соизмеримых кристаллических структур, где пять ячеек $\mathrm{SiC}$ согласуются с четырьмя ячейками Si. B такой ситуации сами каналы отнюдь не являются идеальными, их вид в направлении $\langle 111\rangle$ показан на рис. 6. Лишь 4\% гексагонов $\mathrm{SiC}$ и 7\% гексагонов Si согласованы друг с другом. Различие эффекта каналирования при регистрации рассеяния под разными углами также может интерпретироваться как наличие эпитаксиальной неоднородности.

\section{4. Заключение}

Выполненный ионно-пучковый анализ гетероструктуры $6 H-\mathrm{SiC} / \mathrm{Si}(111)$ подтверждает наличие эпитаксиального соответствия во всей полученной структурной композиции, но при этом свидетельствует о возрастании дефектности слоя от поверхности пленки в глубь к кремнию, связанном с ростом плотности двойников. 
Особенно это касается слоя кремния непосредственно под пленкой $\mathrm{SiC}$, содержащего большое количество пор и пустот. Следует отметить, что при этом в пленке $\mathrm{SiC}$ отсутствуют дислокации несоответствия, являющиеся основным дефектом при росте пленок стандартными методами. Получены рентгеновские и ионно-пучковые данные, позволяющие утверждать не только факт монокристалличности поверхностного слоя карбида кремния в гетероструктуре $6 \mathrm{H}-\mathrm{SiC} / \mathrm{Si}$ толщиной 75 нанометров, но и наличие эпитаксиального согласия между кремниевой подложкой и пленкой карбида кремния.

\section{Список литературы}

[1] L.C. Feldman, J.W. Mayer, S.T. Picraux. Material analysis by ion channeling. Academic Press, N. Y. (1982). 300 p.

[2] Э.Т. Шипатов. Каналирование ионов. Изд-во Ростов. ун-та, Ростов н/Д (1986). 140 с.

[3] High energy ion beam analysis of solids / Eds G. Gotz, K. Gartner. Academic-Verlag, Berlin (1988). 376 p.

[4] В.К. Егоров, Е.В. Егоров, Ю.М. Миронов. В сб.: Научные труды 20-й Межд. научно-техн. конф. „Высокие технологии в промышленности России“. Изд. МГТУ им. Н.Э. Баумана, М. (2015). С. 178.

[5] В.К. Егоров, Е.В. Егоров, М.С. Афанасьев. Наноинженерия. 11, 38 (2012).

[6] S.A. Kukushkin, A.V. Osipov. J. Appl. Phys. 113, 024909 (2013).

[7] S.A. Kukushkin, A.V. Osipov. J. Phys. D 47, 313001 (2014).

[8] С.А. Кукушкин, А.В. Осипов. ФТТ 56, 1457 (2014).

[9] С.А. Кукушкин, А.В. Осипов. ФТТ 58, 725 (2016).

[10] С.А. Кукушкин, А.В. Осипов. ФТТ 56, 761 (2014).

[11] С.А. Кукушкин, А.В. Лукьянов, А.В. Осипов, Н.А. Феоктистов. Письма в ЖТФ 40, 1, 71 (2014).

[12] R.L. Doolittle. Nucl. Instr. Meth. B9, 344 (1985).

[13] С.А. Кукушкин, А.В. Осипов. ФТП 47, 1575 (2013).

[14] J.R. Bird, J.S. Williams. Ion beams for material analysis. Academic Press, Sidney (1989). 719 p. 